\title{
Malignant Atrophic Papulosis
}

National Cancer Institute

\section{Source}

National Cancer Institute. Malignant Atrophic Papulosis. NCI Thesaurus. Code C84835.

A rare disorder of unknown etiology. It may present as a cutaneous disorder with a benign clinical course or a systemic disorder with a grim prognosis. Both the cutaneous and systemic variants are characterized by the presence of papular skin lesions. The systemic variant, in addition to the skin papules, is characterized by gastrointestinal manifestations including abdominal pain and distention, nausea, vomiting, diarrhea, intestinal infarction, and intestinal perforation. The central and peripheral nervous systems may also be involved in the systemic variant. 